Es bestehen keine Interessenkonflikte.

\section{Literatur}

1. Pfeuffer S, Klotz L, Wiendl H. Sicherheitsmaßnahmen und Abwägung der Risiken in der RRMS-Therapie. Der Neurologe und Psychiater 2016; 17 (11): $42-48$

2. Tourbah A, Lebrun-Frenay C, Edan G, Clanet M, Papeix C, Vukusic S. et al. MD1003 (highdose biotin) for the treatment of progressive multiple sclerosis: A randomized, doubleblind, placebo-controlled study. Mult Scler 2016; 22 (13): 1719-31

3. Sedel F, Papeix C, Bellanger A, Touitou V Lebrun-Frenay $C$ et al. High doses biotin in

\title{
Replik der Autoren des Beitrages „Sicherheitsmaßnahmen und Abwägung der Risiken in der RRMS-Therapie" (DNP - Der Neurologe und Psychiater 11/2016, S. 42 ff.)
}

Der Kollege schneidet ein in der Therapie der Multiplen Sklerose zunehmend relevantes Thema an: die (teilweise selbstständig) erfolgende Ko-Medikation und die Konsequenzen im Hinblick auf Diagnostik und Therapie, vor die die betreuenden Kolleginnen und Kollegen dadurch gestellt werden.

Zahlreiche laborchemische Tests bedienen sich antikörpervermittelter Testverfahren (z.B. Elektrochemilumineszenz-Immunoassay (ECLIA)). Die Quantifizierung der zu messenden Stoffe erfolgt hier meist über Enzyme, die mittels "Biotin-Streptavidin"-System an die detektierenden Antikörper gekoppelt werden. Je nach verwendeter Untersuchungstechnik können hierbei Überoder Unterdetektionen in Anwesenheit größerer Mengen von freiem Serum-Biotin vorkommen [1, 2]. Die Halbwertszeit von oral eingenommenem Biotin im Serum ist aufgrund rascher renaler Elimination sehr gering [3]. Dies verrät jedoch nichts über die Dauer möglicher Interferenzen mit verschiedenen Labortests. Die bereits durch Goischke erwähnten Studien bedienten sich eines Richtwertes von drei bis fünf Tagen Karenz [4]. Wir würden hier zwei Schlussfolgerungen ziehen:

1. Angesichts der breiten Anwendung von Streptavidin-abhängigen Immunoassays in der heutigen Labormedizin erscheint die ausreichende Pausierung einer Biotintherapie zwingend erforderlich. Unter Biotineinnahme erfolgte Immunoassays sollten besonders kritisch bewertet und auf Plausibilität überprüft werden. Das den Test durchführende Lalot study. Mult Scler Relat Disord 2015; 4: 159-69

4. Siddiqui U, Egnor E, Sloane JA. Biotin supplementation in MS clinically valuable but can alter multiple blood test results. Mult Scler 2016; First publ. December 7

5. Sotirchos ES, Bhargava P, Eckstein C et al. Safety and immunologic effects of highvs low-dose cholecalciferol in multiple sclerosis. Neurology 2016; 86: 382-90

6. Minkovsky A, Lee MN, Dowlatshahi M, Angell TE, Mahrokhian LS, Petrides AK et al. High-dose biotin treatment for secondary progressive multiple sclerosis may interfere with thyroid assays. AACE Clin Case Rep 2016; 2 (4): e370-e3 chronic progressive multiple sclerosis: A pi-

\section{Hier steht eine Anzeige.}

\author{
Springer
}

bor sollte vor geplanter Diagnostik konsultiert oder - spätestens mit Einsendung der Probe - informiert werden.

2. Im speziellen Fall der Nachsorge nach Alemtuzumabtherapie sollte bei begründetem Verdacht auf das Vorliegen eines sekundären Autoimmunphänomens eine erfolgte Biotineinnahme zwar berücksichtigt und mitgeteilt werden, in jedem Fall ist jedoch die fachärztliche Überweisung angezeigt. Hier sollte keine Verzögerung durch wiederholte Labordiagnostik und Therapiekarenz durch den primär behandelnden Kollegen in Kauf genommen werden.

Dr. med. Steffen Pfeuffer und Kollegen, Universitätsklinikum Münster

\section{Interessenskonflikt}

Die Interessenkonflikte haben sich im Vergleich zum entsprechenden Artikel (siehe oben) nicht geändert.

\section{Literatur}

1. Minkovsky A, Lee MN, Dowlatshahi M, Angell TE, Mahrokhian LS, Petrides AK, et al. High-Dose Biotin Treatment for Secondary Progressive Multiple Sclerosis May Interfere with Thyroid Assays. AACE Clin Case Rep 2016; 2 (4): e370-e3

2. Elston MS, Sehgal S, Du Toit S, Yarndley T, Conaglen JV. Factitious Graves' Disease Due to Biotin Immunoassay Interference-A Case and Review of the Literature. J Clin Endocrinol Metab 2016; 101 (9): 3251 -5

3. Bitsch R, Salz I, Hotzel D. Studies on bioavailability of oral biotin doses for humans. Int J Vitam Nutr Res 1989; 59 (1): 65-71

4. Siddiqui U, Egnor E, Sloane JA. Biotin supplementation in MS clinically valuable but can alter multiple blood test results. Mult Scler 2016 